\title{
Device Handling Problem
}

National Cancer Institute

\section{Source}

National Cancer Institute. Device Handling Problem. NCI Thesaurus. Code C95879.

Handling of the device not in accordance with specification, prior to use on the patient. 